\title{
Premature Rats Treated with Propylthiouracil Show Enhanced Pulmonary Antioxidant Enzyme Gene Expression and Improved Survival during Prolonged Exposure to Hyperoxia
}

\author{
YOUWEI CHEN, ILENE R.S. SOSENKO, AND LEE FRANK \\ Pulmonary Research Center, Departments of Pediatrics and Medicine, University of Miami School of \\ Medicine, Miami, Florida 33101
}

\begin{abstract}
In full-term newborn rats, propylthiouracil (PTU) treatment has been previously shown to decrease susceptibility to $\mathrm{O}_{2-}$ induced lung damage and improve survival during hyperoxic exposure. However, no differences were found in lung antioxidant enzyme (AOE) activity responses to hypcroxia compared with $\mathrm{O}_{2}$-exposed untreated (control) term rats. To further explore possible pulmonary protective effects of PTU treatment in prematurely delivered animals, we administered PTU $(0.015 \%)$ in drinking water to timed-pregnant rats for the final $10 \mathrm{~d}$ of gestation prior to delivery $1 \mathrm{~d}$ before term, and during lactation; control pregnant/nursing rats received untreated water. Both groups of 21-d premature rat pups were randomized to either $>95 \% \mathrm{O}_{2}$ or room air exposure after birth for up to $14 \mathrm{~d}$. The left lungs of 7-d exposure pups were used to quantitate the concentrations of AOE mRNA by solution hybridization; the right lungs of the same pups were assayed for AOE activities. PTU treatment resulted in survival rates of $\mathrm{O}_{2}$-exposed preterm rat pups that were consistently higher at all time periods in hyperoxia including $7 \mathrm{~d}$ [PTU, 67 of $82(82 \%)$ versus control pups, 58 of 113 $(51 \%) ; p<0.001]$ and $14 \mathrm{~d}$ [PTU, 31 of $39(79 \%)$ versus control, 15 of $66(23 \%) ; p<0.001]$. Further evidence of increased tolerance to $>95 \% \quad \mathrm{O}_{2}$ in PTU pups included a significant decrease in the incidence of microscopic intraalveolar edema and a significant increase in lung tissue surfactant-related phospho-
\end{abstract}

ABSTRACT
PTU is a thioamide derivative that inhibits thyroid hormone synthesis and readily crosses the placenta (1). When PTU was administered to pregnant rats, their late gestation fetuses had significantly increased pulmonary AOE (SOD, CAT, and GP) activities compared with age-matched control fetuses, whereas the lung surfactant contents were similar (2). Adult rats pretreated with PTU showed less $\mathrm{O}_{2}$-induced lung damage and

Received December 19, 1994; accepted May 2, 1995.

Correspondence and reprint requests: Youwei Chen, M.D., Pulmonary Research (R120), University of Miami School of Medicinc, P.O. Box 016960, Miami, FL 33101

Supported by the University of Miami School of Medicinc, Pulmonary Research Center, Departments of Pediatrics and Medicine, and by American Lung Association of Florida Carcer Investigator Award (to L.F.). lipids compared with $\mathrm{O}_{2}$-exposed control pups. At $7 \mathrm{~d}$ in high $\mathrm{O}_{2}$ the PTU-treated pups showed greater increases in the lung AOE mRNA levels and AOE activities of catalase and glutathione peroxidase in response to hyperoxia compared with the untreated control $\mathrm{O}_{2}$ group. Thus, we conclude that PTU treatment protects premature rats against $\mathrm{O}_{2}$-induced lung injury and lethality during prolonged hyperoxic challenge. The protective action of PTU may be related, at least in part, to the enhanced pulmonary AOE gene expression in the treated rat pups with resultant increases in protective AOE activity levels in response to neonatal lung oxidant challenge. (Pediatr Res 38: 292-297, 1995)

PTU, propylthiouracil

Abbreviations

AOE, antioxidant enzyme(s)

SOD, superoxide dismutase

CuZnSOD, copper-zinc superoxide dismutase

MnSOD, manganese superoxide dismutase

CAT, catalase

GP, glutathione peroxidase

DSPC, disaturated phosphatidylcholine

TRH, thyrotropin-releasing hormone

$\mathbf{T}_{3}$, triiodothyronine

$\mathrm{T}_{4}$, thyroxine

lethality during exposure to hyperoxia than control rats, as well as greater pulmonary reduced glutathione levels and CAT activity in response to high $\mathrm{O}_{2}$ exposure (3). In a full-term newborn rat study, PTU treatment was recently shown to decrease susceptibility to $\mathrm{O}_{2}$-induced lung damage and consistently improve survival during neonatal hyperoxic exposure; however, no differences were found in the lung AOE activity responses to hyperoxia in the term $\mathrm{O}_{2}$-exposed PTU-treated pups compared with $\mathrm{O}_{2}$-exposed control term rats (4).

To specifically explore possible pulmonary protective effects of PTU in preterm animals, we used a prematurely delivered rat model (previously demonstrated to have a transiently improved hyperoxic survival versus the term rat as well as a 
greater magnitude of hyperoxic induction of lung AOE activities) (5) and examined comparative hyperoxic survival, parameters of pulmonary $\mathrm{O}_{2}$ toxicity, and lung AOE responses to hyperoxia in the growing lungs of PTU-treated and control preterm animals. On the basis of the previous thyroid hormone and anti-thyroid drug treatment studies, we hypothesized that premature rats treated with PTU would demonstrate superior tolerance to prolonged hyperoxic exposure and an associated decreased evidence of $\mathrm{O}_{2}$-induced lung injury.

\section{METHODS}

Animals and treatment. Adult female and male breeder Sprague-Dawley albino rats were obtained from Charles River Laboratories (Wellington, MA). Breeding was accomplished by placing two female rats in the same cage with one male overnight. Probable pregnancy was determined by a positive vaginal sperm smear the next morning, and the onset of gestation was considered to be the midpoint of the cohabitation period. The timed-pregnancy rats were maintained on standard laboratory food and water ad libitum and were kept on a 12-h light/dark cycle in the accredited University of Miami Animal Care Facilities. All portions of the experimental protocol were preapproved by the University of Miami Animal Research Welfare Committee.

Ten days before preterm delivery at gestational d 21 (term $=$ d 22 of gestation), timed-pregnancy rats were randomly assigned to either a PTU treatment group or a control group. PTU (Sigma Chemical Co., St Louis, MO), 0.015\%, was administered in the drinking water, which was made up fresh daily. The control group received drinking water not containing PTU. This regimen has been used previously by others and has been shown to be effective in inhibiting thyroid hormone synthesis without influencing litter size or viability (6). The procedures and dosage of PTU were identical to those used in previously reported full-term newborn rat studies from our laboratories [calculated maternal dose of PTU $\approx 30 \mathrm{mg} / \mathrm{kg} / \mathrm{d}$ (approximately twice the orally administered clinical dosage)]. PTU treatment of mother rats during the final $10 \mathrm{~d}$ of gestation and throughout lactation resulted in inhibited serum $\mathrm{T}_{3}$ and $\mathrm{T}_{4}$ levels in their full-term offspring (4).

At $21 \mathrm{~d}$ of gestation, pregnant rats were anesthetized by intraperitoneal injection of ketamine/xylazine (ketamine:xylazine, $45 \mathrm{mg} / \mathrm{kg}: 5 \mathrm{mg} / \mathrm{kg}$ ) and hysterotomy was performed. The newly delivered pups were rapidly resuscitated by removing the surrounding membranes, drying them vigorously, warming them on heating pads, and applying low flow $\mathrm{O}_{2}(\sim 30 \%)$ for $\sim 30 \mathrm{~min}$.

Hyperoxic exposure. Shortly after delivery and stabilization, all the surviving 21-d premature pups of 3-5 equivalently treated litters were first pooled together and then randomly redistributed to surrogate equivalently treated mother rats (which had recently delivered full-term PTU or control offspring). These equivalently treated surrogate mother rats were then continued on the same treatment during lactation. For each group (PTU-treated or untreated control), one half of the reconstituted litters was placed in $>95 \% \mathrm{O}_{2}$ exposure chambers and one half remained in room air. Some non- experimental full-term newborn rat pups (marked by tail snip) were added at $24 \mathrm{~h}$ and/or $48 \mathrm{~h}$ of exposure when necessary to readjust the litter sizes to 12 pups per dam to ensure equal litter sizes for equivalent nutrition. The procedures and conditions of hyperoxic exposures were as previously described (5). Survival was noted daily during the 14-d exposure period.

Biochemical analyses. Randomly selected $\mathrm{O}_{2}$-exposed and air control pups from each group were killed by an intraperitoneal overdose of pentobarbital after $7 \mathrm{~d}$ of exposure. The procedures of lung perfusion were as previously described (5). The left lungs were used for measuring AOE mRNA concentrations, and the right lungs of the same pups were used for assaying AOE activities.

AOE mRNA quantitation. The rat complementary RNA for CuZnSOD, MnSOD, CAT, and GP were prepared as previously described (7-9). Total nucleic acids were extracted by phenol-chloroform extraction of the left lung tissue homogenate (9). Quantitation of each AOE mRNA was achieved using the solution hybridization assay of Durnam and Palmiter (10). Results of the AOE mRNA concentrations were expressed as the specific AOE mRNA molecules per mg DNA.

AOE activity assays. The right lungs were homogenized in cold $2.5 \mathrm{mM}$ potassium phosphate buffer $(\mathrm{pH} 7.8)$ in an Omni homogenizer (Omni International Inc., Waterbury, CT). The homogenates were centrifuged at $27000 \times g$ for $45 \mathrm{~min}$ at $4^{\circ} \mathrm{C}$. The supernatant fractions were then dialyzed overnight against three changes of $50 \mathrm{vol}$ of $2.5 \mathrm{mM}$ potassium phosphate buffer ( $\mathrm{pH} 7.8$ ) with $0.1 \mathrm{mM}$ EDTA and were subsequently used for analyses of AOE activities using standard spectrophotometric assays for SOD (cytochrome $c$ reduction rate by xanthine-xanthine oxidase) (11), CAT $\left(\mathrm{H}_{2} \mathrm{O}_{2}\right.$ consumption rate) (12), and GP (NADPH oxidation rate with cumene hydroperoxide substrate) (13). The method of differential cyanide inhibition was used to individually quantitate cytosolic CuZnSOD and mitochondrial MnSOD activities (14). All enzyme activities were expressed as activity units per mg DNA. DNA in aliquots of lung homogenates used for AOE mRNA or for AOE activity was extracted and measured using purified calf thymus DNA (Sigma Chemical Co.) as a standard (15).

Surfactant phospholipids and DSPC. The lipids were extracted from lung homogenates using the method of Bligh and Dyer (16). A portion of the lipid extracts was used to isolate DSPC according to Mason et al. (17). The total phospholipids and DSPC content were measured by phosphorus determinations in these fraction (18). A known quantity of $\left[{ }^{14} \mathrm{C}\right]$ dipalmitoyl-phosphatidylcholine (NEN, Boston, MA) was added before lipid extraction to estimate and correct for sequential losses. Lipids were expressed as milligrams/mg of protein. Protein was measured by the Folin-phenol reagent method (19).

Lung pathologic analyses. Randomly selected animals from each group at $14 \mathrm{~d}$ of exposure were killed as above. Unperfused, uninflated left lungs were tied off and removed for assessing lung wet weight/dry weight ratios $\left[80^{\circ} \mathrm{C}\right.$ oven; lung dried until constant weight found $(72 \mathrm{~h})]$. For microscopic studies, the right lungs of those animals were fixed in situ via a tracheal cannula at a constant inflation pressure of $20 \mathrm{~cm} \mathrm{H}_{2} \mathrm{O}$ (fixative, $10 \%$ buffered formalin). The hematoxylin and eosin- 
stained lung sections (right upper, middle, and lower lobes) were first coded and then examined independently by two investigators in a blinded fashion for pathologic changes, looking for evidence of interstitial, perivascular/peribronchiolar, and intraalveolar edema, and lung hemorrhage.

Statistical analyses. Comparative survival data and incidence of intraalveolar edema were compared by $\chi^{2}$ testing. Four group comparisons (PTU air, PTU $\mathrm{O}_{2}$, control air, and control $\mathrm{O}_{2}$ ) were made by analysis of variance and Duncan's multiple range test. Kramer's extension of Duncan's test was used in cases of unequal number of replications (20). For all statistical tests, a $p<0.05$ value was considered a significant difference between the compared values.

\section{RESULTS}

Survival in hyperoxia. Initial survival at $30 \mathrm{~min}$ after premature delivery averaged $90 \%$ for both groups (170/189 for PTU pups and 223/247 for control pups, number alive/total number delivered). The composite survival rates of PTUtreated and control premature rat pups during $14 \mathrm{~d}$ of hyperoxia are illustrated in Figure 1. The survival rate of the PTU-treated pups when placed in $>95 \% \mathrm{O}_{2}$ at birth was consistently higher at all time periods in hyperoxia from 1 to $14 \mathrm{~d}$. However, extensive past experimental experience leads us to believe that the early deaths in hyperoxia (before at least $2 \mathrm{~d}$ of hyperoxia for preterm rat pups) are not due to pulmonary $\mathrm{O}_{2}$ toxicity per se, because approximately $1 / 3$ of the prematurely delivered rat pups fail to survive the first $48 \mathrm{~h}$ of life in room air as well (see legend to Fig. 1).

Lung biochemical responses to hyperoxia. The comparative responses of the pulmonary AOE to $7 \mathrm{~d}$ of hyperoxic challenge in the PTU-treated and control premature rat pups are shown in Figure 2 (for AOE activities) and Figure 3 (for AOE mRNA concentrations). After $7 \mathrm{~d}$ in hyperoxia, both PTU-treated and untreated controls were able to induce an adaptive lung AOE activity response to hyperoxic exposure (except MnSOD). PTU pups exposed to hyperoxia demonstrated significantly greater increases in CAT and GP activities than the untreated control $\mathrm{O}_{2}$ group. The results of lung AOE mRNA concentrations (using the contralateral lungs of the same group of animals) showed the four AOE mRNA levels significantly elevated in the PTU-treated $\mathrm{O}_{2}$-exposed group compared with PTU-treated air-exposed pups and greater increases in the levels of MnSOD mRNA and GP mRNA in the PTU $\mathrm{O}_{2}$ group compared with the untreated $\mathrm{O}_{2}$ group.

The lung tissue DSPC and total phospholipid content responses to $7 \mathrm{~d}$ of hyperoxic exposure are summarized in Table 1. Offspring of PTU-treated dams had significant increases in lung tissue DSPC and total phospholipid contents compared with control offspring in prolonged hyperoxia.

Lung pathologic analyses. The comparative lung wet weight/dry weight ratios (reflection of pulmonary edema) after $14 \mathrm{~d}$ of hyperoxia showed no differences between the PTU-O $(5.95 \pm 0.09, \uparrow 17 \%)$ and control- $\mathrm{O}_{2}(6.03 \pm 0.12, \uparrow 22 \%)$ groups (their respective air control group values were $5.11 \pm$ 0.03 and $4.96 \pm 0.02$, mean $\pm \mathrm{SEM}, n=15-20$ samples/ group). However, when comparing pathologic evidence of more advanced $\mathrm{O}_{2}$ toxicity, intraalveolar edema was found to be present in $46 \%$ ( 11 of 24 ) of the control group lung sections after $14 \mathrm{~d}$ of hyperoxia versus only $17 \%$ (4 of 24) of the PTU group lung sections $(p<0.05)$. Although the similar increases in wet/dry weights in the $\mathrm{O}_{2}$ groups suggest endothelial cell injury was present in both groups, the intraalveolar edema results would seem to suggest a greater degree of injury to the alveolar epithelial cell barrier of lungs of the $\mathrm{O}_{2}$-control group.

\section{DISCUSSION}

Prenatal administration of either thyroid hormone $\left(\mathrm{T}_{3}\right)$ or $\mathrm{TRH}$ to pregnant rats in late gestation produces significantly elevated lung DSPC concentrations, but significantly depressed

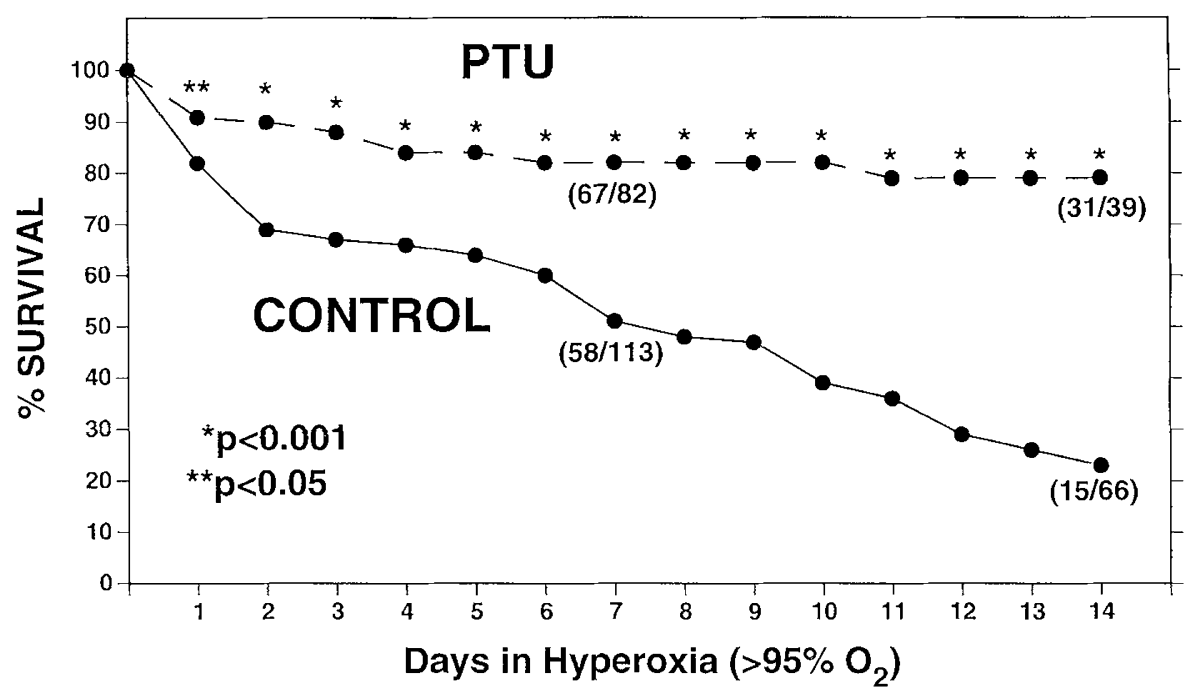

Figure 1. Survival of PTU-treated and control premature rat pups in $>95 \% \mathrm{O}_{2}$ for $14 \mathrm{~d}\left(n / n\right.$, number alive/number put in $\left.\mathrm{O}_{2}\right)$. ${ }^{*}, p<0.001$ and $* *, p<0.05$ for the two $\mathrm{O}_{2}$-exposed group survival rate comparisons. For the pups maintained in room air, the subsequent survival rates for the PTU-treated group were $81 \%$ (at $24 \mathrm{~h}$ ), $75 \%$ (at $48 \mathrm{~h}$ ), and $75 \%$ ( 2 to $14 \mathrm{~d}$ of exposure). For the untreated air control pups, the rates werc $76 \%$ (at $24 \mathrm{~h}$ ), $69 \%$ (at $48 \mathrm{~h}$ ), and $69 \%$ ( $2-14 \mathrm{~d}$ of exposure). 


\begin{tabular}{|ll}
$\square$ Control-Air & $\square$ Control-O \\
PTU-Air & PTU-O $_{2}$ \\
\hline
\end{tabular}
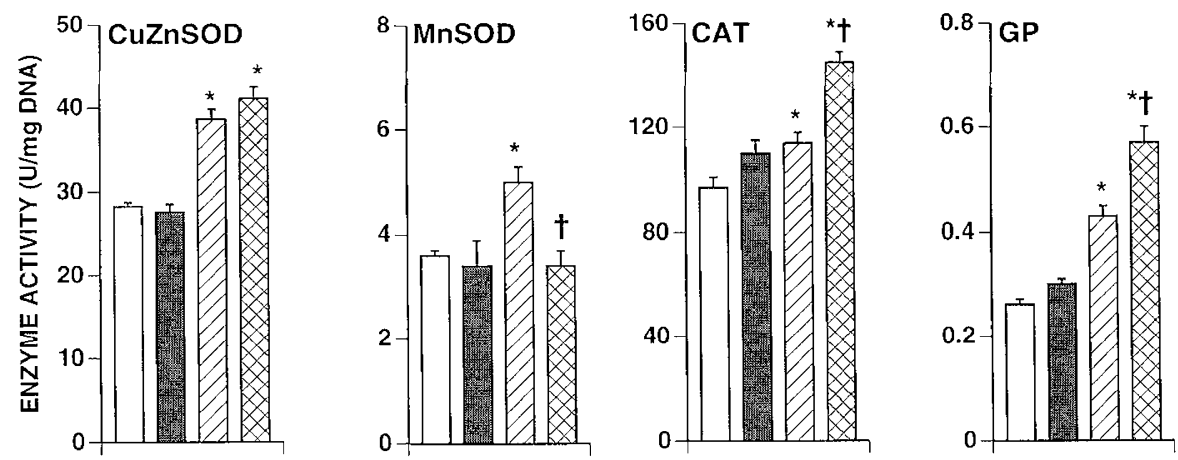

Figure 2. Comparative pulmonary AOE activity levels of PTU-treated and control premature rat pups at $7 \mathrm{~d}$ of hyperoxic $\left(>95 \% \mathrm{O}_{2}\right)$ or room air $\left(21 \%\right.$ O $\left.\mathrm{O}_{2}\right)$ exposure. Rat right lungs were assayed for CuZnSOD, MnSOD, CAT, and GP activities. Values are based on 6 lung samples/group; bars indicate mean \pm SEM. $*, p<0.01$ for $\mathrm{O}_{2}$ group $v$ s respective air group. $\dagger, p<0.01$ for $\mathrm{PTU}-\mathrm{O}_{2}$ group $v s$ control- $\mathrm{O}_{2}$ group values.

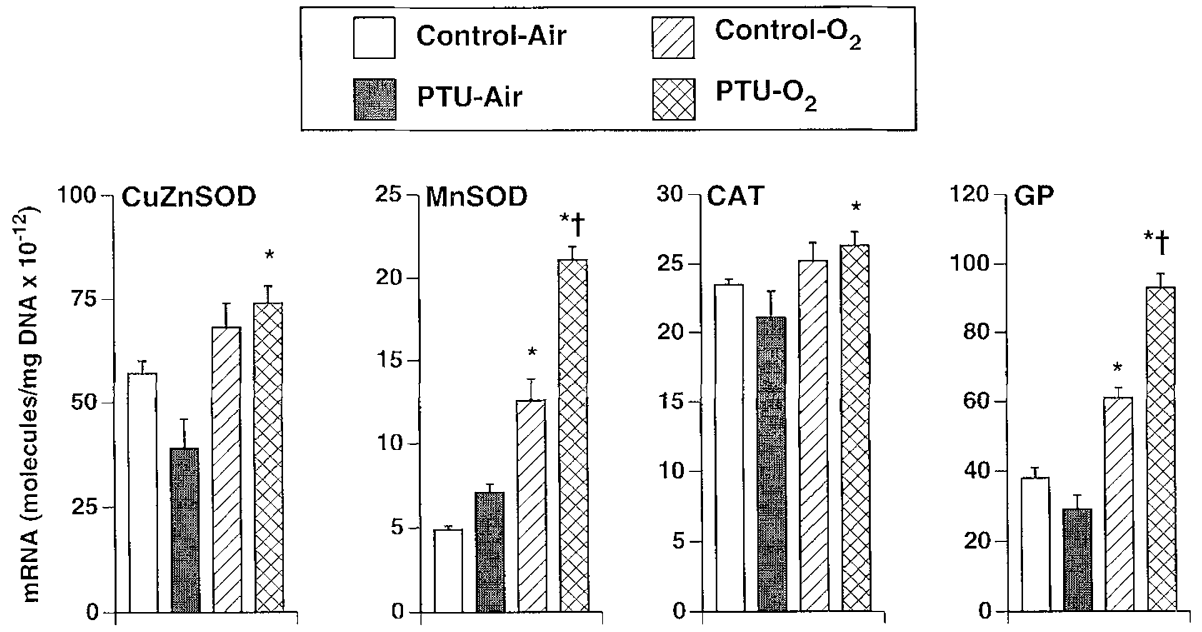

Figure 3. Comparative lung AOE mRNA concentrations of PTU-treated and control premature rat pups at $7 \mathrm{~d}$ of hyperoxic $\left(>95 \% \mathrm{O}_{2}\right)$ or room air $\left(21 \% \mathrm{O}_{2}\right)$ exposure. Rat left lungs from same samples as Figure 2 were assayed for CuZnSOD mRNA, MnSOD mRNA, CAT mRNA, and GP mRNA by solution hybridization using respective ${ }^{35} \mathrm{~S}$-labeled complementary RNA probes. Values are based on 6 lung samples/group; bars indicate mean \pm SEM. *, $p<0.05$ for $\mathrm{O}_{2}$ group vs respective air group. $\dagger, p<0.01$ for PrU- $\mathrm{O}_{2}$ group vs control- $\mathrm{O}_{2}$ group values.

Table 1. Comparative lung surfactant content responses to $7 \mathrm{~d}$ of hyperoxic exposure

\begin{tabular}{ccc}
\hline & $\begin{array}{c}\text { DSPC } \\
(\mathrm{mg} / \mathrm{mg} \text { protein })\end{array}$ & $\begin{array}{c}\text { TPL } \\
(\mathrm{mg} / \mathrm{mg} \text { protein })\end{array}$ \\
\hline Control-air & $0.062 \pm 0.002$ & $0.312 \pm 0.010$ \\
Control- $\mathrm{O}_{2}$ & $0.054 \pm 0.003$ & $0.286 \pm 0.020$ \\
& $(\downarrow 13 \%)$ & $(\downarrow 8 \%)$ \\
PTU-air & $0.068 \pm 0.004$ & $0.343 \pm 0.008$ \\
PTU-O & $0.080 \pm 0.004^{*} \dagger$ & $0.378 \pm 0.008 \dagger$ \\
& $(\uparrow 18 \%)$ & $(\uparrow 10 \%)$ \\
\hline
\end{tabular}

Values are mean \pm SEM for four to five samples/group. TPL, total phospholipid.

$* p<0.05$ vs PTU-air group.

$\uparrow p<0.01$ vs control- $\mathrm{O}_{2}$ group.

fetal lung AOE activities $(21,22)$. After prenatal TRH treatment newly delivered term rats are able, however, to increase their AOE activities markedly in response to hyperoxia, despite their lower baseline (at birth) AOE activity levels (22). Unex- pectedly though, full-term TRH offspring were found to have comparatively poorer hyperoxic survival with increased indices of $\mathrm{O}_{2}$-induced lung damage compared with control newborns in hyperoxia (23). In contrast, when endogenous thyroid hormone production was inhibited by maternal PTU administration, newborn term rats demonstrated decreased susceptibility to $\mathrm{O}_{2}$-induced lung damage and improved survival during hyperoxic exposure not accompanied by increased lung AOE responses to hyperoxia compared with $\mathrm{O}_{2}$-control term rats, nor by any decreased lung tissue $\mathrm{O}_{2}$ radical formation in high $\mathrm{O}_{2}(4)$.

We hypothesized in the present study that, similar to term rats, preterm rats treated pre- and postnatally with PTU would likewise demonstrate superior tolerance to prolonged hyperoxic exposure and an associated decreased evidence of $\mathrm{O}_{2}-$ induced lung injury. Indeed, in addition to the consistent and dramatically superior survival rate of the PTU-treated preterm offspring in hyperoxia, we found concomitant evidence of 
increased protection against $\mathrm{O}_{2}$-induced lung damage in the DSPC/phospholipid data and in the comparative intraalveolar edema results during $\mathrm{O}_{2}$ exposure. These findings in premature rats are therefore in agreement with previous studies either in adult rats (3) or in full-term newborn rats (4), in which decreased susceptibility to $\mathrm{O}_{2}$-induced lung damage and improved hyperoxic survival after PTU treatment were reported. However, our PTU-treated premature pups showed greater increases in their lung CAT and GP activities in response to hyperoxic exposure compared with the untreated control $\mathrm{O}_{2}$ group, a finding consistent with results in adult rats (3). Our PTU-treated preterm animal results differ importantly from the findings in PTU-treated full-term newborn rats which respond to neonatal hyperoxic challenge with no greater elevations in pulmonary AOE activities than control- $\mathrm{O}_{2}$ pups (4).

The discrepancies in the biologic/biochemical responses to hyperoxic exposure between full-term newborn and preterm rat pups are actually not as unique as they first appear to be. For example, whereas prenatal dexamethasone administration to preterm rats has been shown to enhance survival and increase the activities of lung CAT and SOD at birth, the same prenatal dexamethasone treatment to term rats did not produce changes in AOE activities (23). Similarly, prenatal TRH-treated fullterm rat pups demonstrated decreased survival rates during hyperoxic exposure versus $\mathrm{O}_{2}$-exposed controls (24); however, the same prenatal TRH treatment to preterm pups resulted in no significant differences in hyperoxic survival versus untreated control- $\mathrm{O}_{2}$ premature animals (our unpublished observation). For the PTU studies, the differences in the premature versus term newborns' lung AOE responses to high $\mathrm{O}_{2}$ exposure may suggest that the mechanism of PTU's protective effect against $\mathrm{O}_{2}$ toxicity is related to the induction of pulmonary AOE in the preterm (versus term) animal model.

It is believed that thyroid hormone is able to bind to DNA sequences near to specific genes and thereby "regulate" (promote or inhibit) transcription of these genes-much like glucocorticoid hormone does $(25,26)$. The molecular biology studies herein were undertaken to provide insight into the mechanism by which PTU treatment might be affecting or altering gene expression of the protective AOE under hyperoxic conditions. Analyzing the data in Figures 2 and 3, we found that in untreated control preterm lungs primarily a pretranslational mechanism of AOE gene expression (with increased $\mathrm{AOE}$ activities associated with increased $\mathrm{AOE}$ mRNA) could be involved in the pulmonary response to high $\mathrm{O}_{2}$ exposure. The effects of PTU administration on protecting premature rat pups against $\mathrm{O}_{2}$-induced lung injury during hyperoxia may be related, at least in part, to PTU's (direct or indirect) effect on enhancing lung AOE gene expression. For certain enzymes, e.g. CAT, this enhancing effect appears to depend on a pretranslational mechanism only (CAT mRNA and CAT activity both increase by $\sim 30 \%$ ). Whereas for other enzymes (e.g. CuZnSOD, MnSOD, and GP), the altered gene expression may be more complex following PTU administration and may involve combinations of pretranslational and/or translational/posttranslational mechanisms of control.
PTU is a thioamide derivative that is known to cross the placenta, inhibit thyroid hormone synthesis by blocking the incorporation of iodine, and also inhibit the peripheral deiodination of $T_{4}$ to $T_{3}(1)$. The consistently decreased serum $T_{3}$ and $\mathrm{T}_{4}$ levels found in the PTU-treated full-term rat pups in our previous study (4) confirm the effectiveness of maternal PTU treatment in reducing thyroid hormone production in the offspring when it is administered in the pregnant/lactating animal's water source. Older studies indicate a protective pulmonary effect of induced hypothyroidism against the oxidant stress of hyperoxia (27) and/or exposure to ozone (28). Interestingly, in addition to PTU's well known antithyroid properties, PTU has recently been reported to be an effective $\mathrm{O}_{2}$ radical scavenger and to act as an efficient inhibitor of lipid peroxidation (29). It is, in fact, currently being used successfully to treat alcoholic liver disease (30), a condition which has been associated with excess superoxide radical production by hepatic microsomal fractions (31). Thus, it is possible that in addition to enhancing the pulmonary $\mathrm{AOE}$ activity responses to hyperoxic challenge, PTU's marked protective effect against $\mathrm{O}_{2}$ toxicity in the premature rat may also stem from its direct antioxidant properties, its antithyroid properties and its effect on $\mathrm{O}_{2}$ metabolism, or to a combination of these actions.

Finally, further investigation of the mechanism for the protection of premature rats against $\mathrm{O}_{2}$-induced lung injury and lethality by PTU treatment will be required before PTU treatment can be considered for protecting the lung of premature infants from toxic damage associated with required high oxygen therapy.

Acknowledgment. The authors thank Miguel Martinez for his expert technical assistance.

\section{REFERENCES}

1. Wilson JD, Foster DW 1985 Neuroendocrinology. In Williams RH (ed) Textbook of Endocrinology. WB Saunders, Philadelphia, pp 510-514

2. Soscnko IRS, Frank L 1989 Thyroid inhibition and developmental increases in fetal rat lung antioxidant enzymes. Am J Physiol 257:L94-L99

3. Yam J, Roberts, RJ 1979 Pharmacological alteration of oxygen-induced lung toxicity. Toxicol Appl Pharmacol 47:367-375

4. Rodriguez-Pierce M, Sosenko IRS, Whitney P, Frank L 1994 Propylthiouracil treatment decreases the susceptibility to oxygen radical-induced lung damage in newborn rats exposed to prolonged hyperoxia. Pediatr Res 35:530-535

5. Chen Y, Whitney PL, Frank L 1994 Comparative responses of premature versus full-term newborn rats to prolonged hyperoxia. Pediatr Res 35:233-237

6. Cooper DS, Kieffer JD, Halpern R, Saxe V, Mover H, Maloof F, Ridgway EC 1983 Propylthiouracil (PTU) pharmacology in the rat. II. Effects of PTU on thyroid function. Endocrinology 113:921-928

7. Chen Y, Whitney PL, Frank L 1993 Negative regulation of antioxidant enzyme gene expression in the developing fetal rat lung by prenatal hormonal treatments. Pediatr Res 33:171-176

8. Chen Y, Frank L 1993 Differential gene expression of antioxidant enzymes in the perinatal rat lung. Pediatr Res 34:27-31

9. Hass MA, Iqbal J, Clerch LB, Frank L, Massaro D 1989 Rat lung Cu, Zn superoxide dismutase. Isolation and sequence of a full-length cDNA and studies of enzyme induction. J Clin Invest 83:1241-1246

10. Durnam DM, Palmiter RD 1983 A practical approach for quantitating specific mRNAs by solution hybridization. Anal Biochem 131:385-393

11. McCord JM, Fridovich I 1969 Superoxide dismutase: an enzymic function for erythrocuprein (hemocuprein). J Biol Chem 244:6049-6055

12. Holmes RS, Masters CJ 1970 Epigenetic interconversions of the multiple forms of mouse liver catalase. FEBS Let 11:45-48

13. Paglia DE, Valentine WN 1967 Studies on the quantitative and qualitative characterization of erythrocyte glutathione peroxidase. J Lab Clin Med 70:158-169

14. Iqbal J, Whitney P 1991 Usc of cyanide and diethyldithiocarbamate in the assay of superoxide dismutases. Free Rad Biol Med 10:69-77

15. Schneider WC 1957 Determination of nucleic acids in tissue by pentose analysis Methods Enzymol 3:680-684 
16. Bligh EG, Dyer WJ 1959 A rapid method of total lipid extraction and purification. Can J Biochem Physiol 37:911-917

17. Mason RJ, Nellenbogen J, Clements JA 1976 Isolation of disaturated phosphatidylcholine with osmium tetroxide. J Lipid Res 17:281-284

18. Morrison WR 1964 A fast, simple and reliable method for the microdetermination of phosphorus in biological matcrials. Anal Biochem 7:218-224

19. Lowry OH, Rosebrough NJ, Farr AL, Randall RJ 1951 Protein measurement with the Folin phenol reagent. J Biol Chem 193:265-275

20. Steel RGD, Torrie JH 1960 Principles and Procedures of Statistics. McGraw-Hill, New York, pp 107-114

21. Sosenko IRS, Frank L 1987 Thyroid hormone depresses antioxidant enzyme maturation in fetal rat lung. Am J Physiol 253:R592-R598

22. Rodriguez MP, Sosenko IRS, Antigua MC, Frank L 1991 Prenatal hormone treatment with thyrotropin releasing hormone and with thyrotropin releasing hormone plus dexamethasone delays antioxidant cnzyme maturation but does not inhibit a protective antioxidant enzyme response to hyperoxia in newborn rat lung. Pediatr Res 30:522-527

23. Keeney SE, Mathews MJ, Rassin DK 1993 Antioxidant enzyme responses to hyperoxia in preterm and term rats after prenatal dexamethasone administration. Pediatr Res 33:177-180
24. Rodriguez-Pierce M, Sosenko IRS, Frank L 1992 Prenatal thyroid rcleasing hormone and thyroid releasing hormone plus dexamethasone lessen the survival of newborn rats during prolonged high $\mathrm{O}_{2}$ exposure. Pediatr Res 32:407-411

25. Evans RM 1988 The steroid and thyroid hormone receptor superfamily. Science 240:889-895

26. Samuels HH, Forman BM, Horowitz ZD, Ye Z-S 1988 Regulation of gene expression by thyroid hormone. J Clin Invest 81:957-967

27. Clark JM, Lambertsen CJ 1971 Pulmonary oxygen toxicity: A review. Pharmacol Rev 23:37-133

28. Fairchild EJ, Graham SL 1963 Thyroid influence on the toxicity of respiratory irritant gases, ozone and nitrogen dioxide. J Pharmacol Exp Ther 139:177-184

29. Hicks M, Wong LS, Day RO 1992 Antioxidant activity of propylthiouracil. Biochem Pharmacol 43:439-444

30. Orrego H, Blake JE, Blendis LM, Compton KV, Isreal Y 1987 Long-term treatmen of alcoholic liver disease with propylthiouracil. N Engl J Med 317:1421-1427

31. Fernandez V, Barrientos X, Kipreos K, Valenzuela A, Videla LA 1985 Superoxide radical gencration, NADPH oxidase activity, and cytochrome P-450 content of rat liver microsomal fractions in an experimental hyperthyroid state: Relation to lipid peroxidation. Endocrinology 117:496-501 